University of Nebraska - Lincoln

DigitalCommons@University of Nebraska - Lincoln

Faculty Publications, Department of Child, Youth, and Family Studies

Child, Youth, and Family Studies, Department of

October 1984

\title{
The Age Group Labels and Categories of Preschool Children
}

Carolyn P. Edwards

University of Nebraska-Lincoln, cedwards1@unl.edu

Follow this and additional works at: https://digitalcommons.unl.edu/famconfacpub

Part of the Family, Life Course, and Society Commons

Edwards, Carolyn P., "The Age Group Labels and Categories of Preschool Children" (1984). Faculty Publications, Department of Child, Youth, and Family Studies. 9.

https://digitalcommons.unl.edu/famconfacpub/9

This Article is brought to you for free and open access by the Child, Youth, and Family Studies, Department of at DigitalCommons@University of Nebraska - Lincoln. It has been accepted for inclusion in Faculty Publications, Department of Child, Youth, and Family Studies by an authorized administrator of DigitalCommons@University of Nebraska - Lincoln. 


\title{
The Age Group Labels and Categories of Preschool Children*
}

\section{Carolyn Pope Edwards}

\begin{abstract}
Questions of how young children use "age" groups to understand the social world led to 2 studies exploring the content of preschool children's age group labels and categories. Study 1 included 32 children aged 2-4 years and determined spontaneous labels for both photographs and dolls representing the life span. Results indicated that children readily labeled all ages using a relatively limited set of terms, but showed less patterned labeling of stimuli representing adults than children. Girls' labels were more structured than boys'. Older preschoolers showed more differentiated structures than did younger ones and used more kinship terms as labels. Study 2 , on 84 children aged $3-5$, was a photograph-sorting task that determined the points of transition between age categories as well as subjects' own self-identification by age group. Results indicated that preschoolers used a nonadult method of dividing up the life span. Older children made fewer errors. Age self-identification was congruent with how children sorted photos of unfamiliar peers. However, younger boys and girls differed in their self-identification, perhaps reflecting differences in gender identification processes.
\end{abstract}

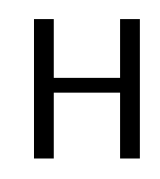

ow to make sense of the immensely diverse and dynamic human world around them is a task that faces all young children as they seek to understand social interaction and to gain predictable responses from others. Recent research has shown that even infants and toddlers have more elaborate social networks than was previously realized, comprising relationships with mother, father, siblings, and peers; and certainly by preschool age most youngsters encounter on an almost daily basis a broad array of familiar and unfamiliar people in many different kinds of settings. Yet, because most of the category systems that are important to adults, such as occupation, social class, and ethnic, political, and community affiliation, are too abstract (Furth, 1980), the young child is forced to rely on social categories related to only the most static and overt cues. Hence age, gender, and familiarity are the attrib-

\footnotetext{
* Published in Child Development 55 (1984), pp. 440-452. Copyright ( 1984 by the Society for Research in Child Development, Inc. All rights reserved. Used by permission.
} 
utes that the child may first use to differentiate the human array (Lewis \& Feiring, 1979). In fact, Kohlberg (1966) has suggested that the age-size differentiation (babies/boys and girls/grown-ups) is the earliest categorization that the child imposes on the social environment, preceding even the gender distinction. Behavioral studies indicate that infants (in one study as young as 3 months) respond and initiate quite differently to other infants than they do to either familiar or unfamiliar adults (Field, 1979; Fogel, 1979). Infants also behave differently to children than they do to adults (Brooks \& Lewis, 1976). As children grow older, they develop a complex "curriculum" for social interaction in which the relative age of the other is a strong predictor of what a child will actually do (Whiting \& Whiting, 1975). By age 2 or 3 , children associate particular "social functions" (or types of social interaction, such as nurturance, dependency, etc.) with particular ages of "social partners" (Edwards \& Lewis, 1979).

Yet despite their functionality for the preschool child, the earliest category systems related to age groups have received little attention from developmental psychologists. However, we do understand the development throughout the childhood years of at least three relevant social-cognitive processes, and we can describe how preschoolers' cognitive limitations cause them to have nonadult understandings of age.

The first process concerns judging or assessing chronological age. The evident interest of preschoolers in "age" differences and comparisons between people clearly does not derive from an ability to accurately judge chronological age. That task is extremely difficult and eludes children younger than age 10 or so (Stevenson, Miller, \& Hale, 1967) because it requires understanding a linear, quantitative scale of increasing years. Preschoolers' judgments of "older" and "younger" are largely fused with "bigness" and/or "smallness" (Britton \& Britton, 1969; Clark, 1972; Piaget, 1969), and their error rate is high when size cues are put into conflict (Kratochwill \& Goldman, 1973; Kuczaj \& Lederberg, 1977; Looft,1971; Looft, Rayman, \& Rayman, 1972). The judgments of" older preschoolers may not be based entirely on size, however, because Kogan, Stephens, and Shelton (1961) held the size of stimuli constant by using passport photos and demonstrated that $50 \%$ of their 4 -year-old and $90 \%$ of their 5 year-old sample showed better-than-chance agreement with adults in the age ranking of faces representing the life span. These older preschoolers had a beginning awareness of hair and facial indicators of elderly age. In general, preschoolers perform better at making relative age judgments when the stimulus materials are more realistic (Kratochwill \& Goldman, 1973). They are able to judge female stimuli as accurately as male ones (see abovementioned studies). 
A second process concerns understanding of social roles. Toddlers use a few social categories such as "baby," "kid," and "man" as simple labels. Children do not begin to define a social category (e.g., "child") in relation to its complement (e.g., "adult") until age 31/2-4 (Watson \& Fischer, 1980). Then, in terms of thinking about transformations, they can mentally operate on only one dimension at a time (such as age or gender) until age 6 or 7 , causing interesting distortions in reasoning about parent and child roles (Fischer \& Watson, 1981).

The third process concerns children's kinship knowledge. Two of children's earliest social labels, "mommy" and "daddy," are sometimes overextended to include people other than parents (Brooks-Gunn \& Lewis, 1979; Greenfield, 1973; Thomson \& Chapman, 1977). Research on children's acquisition of kinship knowledge has established that preoperational children define kinship terms categorically, that is, in terms of concrete attributes related to age and sex, rather than relationally, that is, in terms of descent or marriage links (Chambers \& Tavuchis, 1976; Danziger, 1957; Elkind, 1962; Haviland \& Clark, 1974; Jordan, 1980; Piaget, 1928). For example, young children insist that old men cannot be "fathers" because they must be "grandfathers." However, while stressing preschoolers' conceptual limitations, at least the literature indirectly implies that preschoolers sometimes use kinship terms as labels to designate sex/age groups in society.

The relative neglect of research on preschool children's social categories suggests the need for a close study of this age group. First, a study was conducted to elicit from children aged 2-4 years terms of reference for stimuli representing the life span. This study used both doll and photographic stimuli in order to make it likely that results were not idiosyncratic to one task.

Following Daum (1978), the age labels produced by children are termed "age ascriptions," but it is not presumed that the labels necessarily correspond one-to-one to underlying concepts. Young children possess nonlinguistic concepts onto which words have not yet been mapped (Smith, 1978); they also may respond appropriately to a word on a comprehension task that they do not produce on a labeling task (Anglin, 1978). Nevertheless, it is presumed that children learn terms of reference for those categories that are salient and significant in their dealings with the world (Anglin, 1977), and age group terms appear to be socially useful and highly interesting to children. This study determines children's working vocabulary-what terms of reference 
they most use-as they attempt to label a social array varying in age and gender. It is claimed that their use of labels indicates which age groups are most noticeable to them and also what kinds of people they find to be perceptually or functionally similar (Nelson, Rescorla, Gruendal, \& Benedict, 1978). Brooks-Gunn and Lewis (1979) found that toddlers aged 19-22 months could readily label baby and adult photographs (usually using terms, "baby," "mommy," "daddy," "lady," and "man"), but they had much more difficulty with photographs of children. The present study uses an older age group of subjects and stimuli representative of a much greater array of target ages. The format of the task was designed to highlight the dimension of age for the children in that all doll or photo stimuli were spread out at once on a table before the child so that they could be easily contrasted.

Three questions were addressed. The first hypothesis was that the stimuli that would be the most difficult for children to label would be the adult stimuli. This hypothesis follows from Britton and Britton's(1969) conclusion that 2-4-year-olds cannot age order drawings representing adults and merge "all persons past the young adult level in one big category" (p. 459). The alternate hypothesis was that the child stimuli would present the greatest difficulty based on Brooks-Gunn and Lewis's (1979) above-mentioned finding for toddlers.

The second question concerned age differences within the sample. Older preschoolers were hypothesized to respond, relative to younger ones, with (1) more structure or pattern (vs. nonpatterned responding), and (2) more differentiations (age group distinctions) made between stimuli, The alternative hypothesis, that subject age differences do not occur, would emerge if children's use of age group terminology undergoes few developments during years $2-4$. The alternate hypothesis seemed unlikely but worth examining because processes of chronological age assessment and kinshipterm definition undergo their major transformations during the elementary rather than preschool years.

The third question concerned sex differences. Girls were hypothesized to perform more maturely than boys. Many prior researchers studying age and kinship knowledge have mentioned significant or nonsignificant trends to favor young girls(Britton \& Britton, 1969; Chambers \& Tavuchis, 1976; Danziger, 1957; Jordan, 1980; Kogan et al., 1961; Kratochwill \& Goldman, 1973; LeVine \& Price-Williams, 1974). The alternative hypothesis, that no sex differences would be found, would be inline with Schantz's (1975) general conclusion concerning social-cognitive tasks. 
Because age labels were so easily elicited by Study 1 and because there was so much consensus in their application, a further study was conducted to find out to what chronological age breaks the most common labels actually corresponded, and to investigate children's own age group self-concept.

\section{Study 1}

This study determined children's terms of reference for photographs and dolls representing the life span.

\section{Method}

Subjects. Children were tested at a university laboratory school in a semirural area. Sixteen girls and 16 boys (age range 2.02 to 5.00 ; mean 3.54 girls, 3.50 boys) were interviewed. The older half of the sample was drawn from the "3-4-year-old" classroom, the younger half from the "2-year-old" classroom. All children tested were Caucasian; however, they came from diverse backgrounds in terms of parental education and occupations.

Procedures. In order to discover children's spontaneous age group labels, both dolls and photographs of faces were used. The photos were head-and-shoulder color Polaroid snapshots of unfamiliar people taken from a fixed 10-foot distance; thus, represented face size varied as a function of real size. To provide a sampling of stimuli, two comparable sets of photos (A and B) were used, each including 12 photos: males and females aged $60,30,15,7,3$, and 1 years old. The persons who posed for the pictures were chosen to be representative exemplars of their age group, that is, they "looked their age" (confirmed through pilot testing with adults and elementary school children). The hairstyles and clothing of the persons photographed were deliberately not standardized because examining the relative salience of normal age cues was not the focus of the study, and it was desired that photos be realistic.

The dolls consisted of 10 extremely realistic dollhouse figures representing five age groups. The set included mother and father (approximately 5.5 inches), grandparents (5 inches), older brother and sister (3.7 inches), younger brother and sister (3 inches), and boy and girl babies ( 2 inches). Clothes and body proportions varied according to 
age and sex in conventionally stylized ways. The dolls were "Caucasian" to match the sample children's race.

Testing with photos always preceded testing with dolls because pilot work indicated that the younger subjects would not respond to photos after seeing dolls. The tester (a female college student) seated the child and spread out in shuffled arrangement the set of 12 photos (either set A or B, randomized for sex and age of subject). The tester recorded any labels spontaneously offered by the child, then pointed to either infant picture and asked, "What do you call this one?" All children immediately said, "Baby!" or "Little baby!" The tester continued by saying, "You called that one a baby. What do you call this one?" (pointing to another photo). The tester then proceeded to each picture in turn asking, "What do you call this one?"

Testing with the dolls followed a similar procedure. The dolls were spread out in a random arrangement before the child, and he or she was always allowed to handle them as much as desired.

\section{Results and Discussion}

Question one concerned which stimuli children were unable to label. Virtually all children labeled all stimuli. (Two children labeled $95 \%$ and $86 \%$ of stimuli only.) The mean number of labels produced per stimulus was 1.1. Thus, in contrast to Brooks-Gunn and Lewis's (1979) toddler sample, these preschoolers readily labeled child as well as baby and adult representations. (In the quantitative analyses to follow, only the subjects' finallabels for each stimulus were used.)

Not only did most children label all of the stimuli, but they usually treated the male and female of each age pair in a linguistically similar way. Although the stimuli had been presented to the children in random, non-ordered arrangements, most children produced labels that treated the social array as if it consisted of sets of age/sex pairs. Children sometimes called both male and female members of a particular age pair by the same label (e.g., "grown-up"); more often they used a pair of labels marked for both age group and gender (e.g., "lady" and "man").

This suggests how early children acquire a conceptual and linguistic matrix of the social world based on categories usually differentiated by both age and sex. That is, the supraordinate terms of reference, male and female (similarly, child and adult), are 
too high in the conceptual hierarchy to be basic concepts (Anglin, 1977), first acquired by young children. Rather, the more specific terms, baby, boy, girl, man, and woman (or their meaning equivalents), are probably learned earlier and used more frequently by young children because they correspond most closely to the perceptual and functional distinctions salient to preschool children.

In total, only 10 different "sets" of labels were used: (1) baby (sometimes modified by "little," "big," or "tiny"; (2) boy, girl (sometimes modified by "little," "big," "happy," or "sad"; (3) man, lady (or variants guy, woman, big lady); (4) old man, old lady, (5) child (or kid); (6) grown-up; (7) person (or doll); (8) brother, sister (sometimes modified by "big" or "little"); (9) father, mother (or variants daddy, dad, mommy, mom, and motherin-law); and (10) grandfather, grandmother (or variants grandpa, granddad, grandma, grammie, etc.). In fact, many linguistically appropriate labels were not produced, notably toddler and teenager, the adolescent stimuli were usually labeled as adults. Also, the terms, son, daughter, grandson, and granddaughter were rarely used. Chambers and Tavuchis (1976) also found that these four kinship terms are more difficult for children to use than other kinship terms.

When a child's responses to a pair of stimuli did not fit one of these 10 label sets (e.g., the response pairs Johnny/boy, or mother/grandfathen), the answer was classified as (11) mixed answer. Unclassifiable and nonresponses were coded (12) other. Occasionally a child made a gender error in labeling, for example, calling the photos of both the 3-year-old male and female girl. These gender errors were counted, but the responses were still coded for label, in this example, label 2.

The number of older versus younger subjects displaying each of the 10 label sets to each stimulus condition is shown in Table 1 . These data are not broken down by subjects' sex because analysis revealed no significant sex differences in relative use of the various response categories except for mixed answers and gender errors. 
The Age Group Labels and Categories of Preschool Children

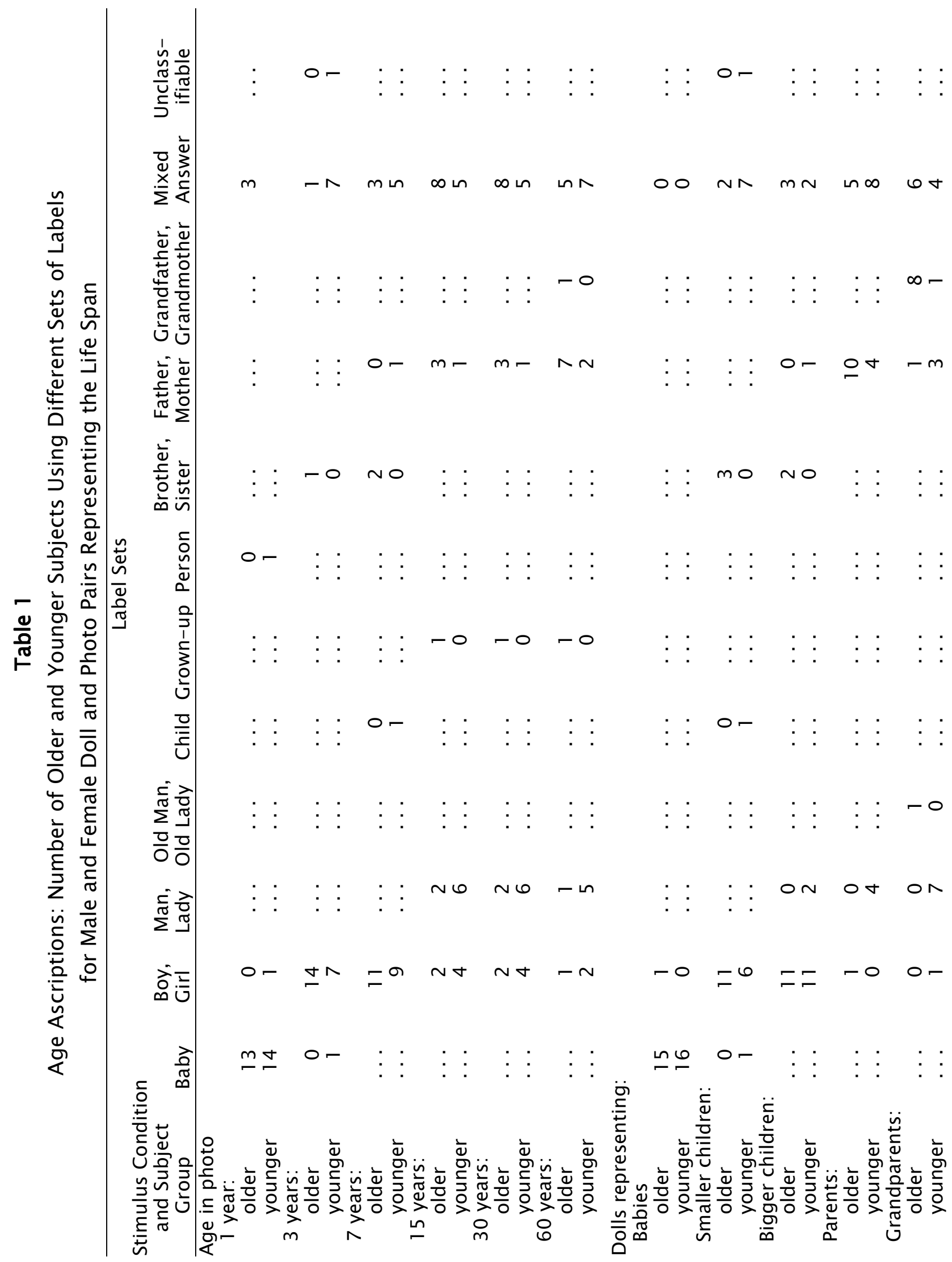




\section{CAROLYN POPE EDWARDS}

Table 1 shows that mixed answers were produced more often for adult (including adolescent) stimuli than for child (including infant) stimuli. If question 1 is now extended to ask which stimuli children had the most difficulty labeling in an orderly or structured way, then the findings suggest that the adult stimuli were hardest. On average each subject labeled only $19.8 \%$ of the infant/child photos using mixed answers, versus $40.6 \%$ of the adolescent/adult photos, $p<.01$ by repeated measures, $t(31)=3.21$, two-tailed. With dolls the comparison was $14.6 \%$ versus $35.9 \%, t(31)=$ 2.67, $p<.05$, for the infant/child versus adult stimuli. Thus, the findings more closely resembled Britton and Britton's (1969) conclusion that preschoolers can better discriminate pictures representing younger ages than they do Brooks-Gunn and Lewis's (1979) conclusion describing toddlers' labeling behavior.

Questions 2 and 3 concerned differences by age and sex within the sample. The sample was divided into four sex/age groups (of $N=8$ ). The mean ages of the subgroups were 2.85 and 4.23 (girls) and 2.85 and 4.15 (boys). For analyses on the photo data, stimulus condition (photo set A or B) also always entered as a factor.

Number of mixed answers averaged 1.2 doll pairs and 1.8 photo pairs per subject. A sex $\times$ age ANOVA revealed that neither age nor stimulus condition were significant factors. Only the sex effects attained or approached significance: for photos, $F(24,1)=$ 5.61, $p<.05$, with $\bar{X}_{\mathrm{G}}=1.4$ and $\overline{\mathrm{X}}_{\mathrm{B}}=2.2$ for girls and boys; for dolls, $\boldsymbol{F}(28, \mathrm{I})=3.48, p$ $=.07$, with $\bar{X}_{C}=0.9$ and $\bar{X}_{B}=1.4$. Boys also made more gender errors than did girls because they were more frequently misled by long or wavy hair on males. For photo gender errors, $\boldsymbol{F}(24, \mathrm{I})=4.99, p<.05$, with $\bar{X}_{\mathrm{G}}=3.1 \%$ and $\bar{X}_{\mathrm{B}}=7.8 \%$; for dolls very few gender errors occurred. Integrating these two findings, it appears that girls responded more to the underlying pairwise structure of the stimuli than did boys.

While older and younger subjects thus did not differ in terms of degree of structuring, older subjects did make more differentiations between stimuli. This question involved analyzing whether each subject did or did not make an age group differentiation between every two stimuli that were adjacent in represented age, but of the same gender.

In order to code whether a subject age-distinguished a particular pair of adjacent stimuli (e.g., the father and grandfather dolls), criteria were developed based on the initial assumption that preschoolers fundamentally distinguish at least three age groups: baby, child, and adult (Kohlberg, 1966). Do preschoolers frequently use labels 
to further divide these three basic age categories into any subgroups? It is demonstrable that at least some of the preschoolers in this study made further distinctions, if two additional assumptions are allowed: (1) that the distinction between parents and grandparents that was made by so many of the subjects does represent an age group distinction (roughly corresponding to middle vs. old age), and (2) that the distinction between a little versus a big child that was made by a few of the subjects also represents an age group distinction. A simple tree diagram (Fig. 1) summarized the ways in which subjects sometimes made age group distinctions; the terms in smaller print indicate some alternative labels used for each.

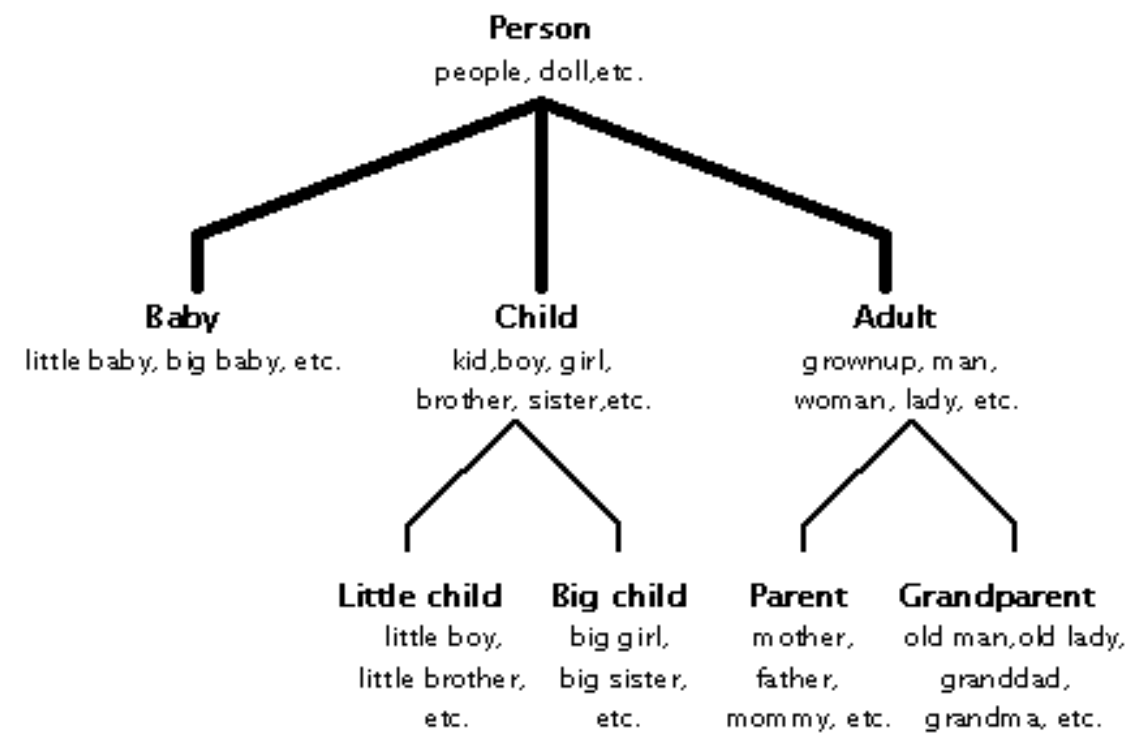

Figure 1. Tree diagram of age group classes and subclasses used to label dolls and photographs by children aged 2-4 years.

The set of doll stimuli actually contained eight possible distinctions to be made: those between baby boy and little boy, little versus big boy, big boy versus father, father versus grandfather, and likewise for female dolls. The photo stimuli had 10 possible distinctions: those listed above, plus those involving male and female adolescents. Each subject was coded for which of the possible distinctions he or she made.

A sex $\times$ age ANOVA indicated that older subjects made many more age distinctions than did the younger subjects, thus confirming the second hypotheses: for dolls, $F(28,1)=10.52, p<.01$, with $\bar{X}_{O}=5.19$ and $\bar{X}_{Y}=3.50$ for older and younger subjects, respectively; for photos, $\boldsymbol{F}(24,1)=5.67, p<.05$, with $\bar{X}_{O}=5.06$ and $\bar{X}_{Y}=3.44$. However, boys and girls did not show the hypothesized difference. Again, not surpris- 
ingly, the dolls were "easier" than photo stimuli for the children to deal with, for children made $54.3 \%$ of the possible doll differentiations versus only $42.5 \%$ of the photos, $p<.01$, by repeated measures, $t(31)=3.35$. Stimulus condition (photo set $\mathrm{A}$ or $\mathrm{B}$ ) was not significant.

Which particular distinctions were made more often by the older than by the younger subjects? All of them, with significant differences, were found for the father versus grandfather dolls $(\phi=5.0, p<.05)$, and mother versus grandmother dolls $(\phi=8.03$, $p<.01$ ). Younger children tended to call all adult stimuli man and lady, whereas older children used kinship terms to distinguish elderly from middle-aged adults. Thus, only our younger preschoolers tended to do as Britton and Britton (1969) had found and "lump all persons past the young adult [adolescent] level in one big category " The older preschoolers seemed to consider old-age cues (e.g., facial wrinkles, gray hair, baldness) in addition to head size when labeling adults (see Kogan et al., 1961).

It is interesting that kinship terms seemed to be more generally available to older children than to younger ones. The older children produced more child kin terms (mainly brother and sister), $F(28,1)=6.28, p<.05$, with $\bar{X}_{O}=0.94$ and $\bar{X}_{Y}=0$; more parent terms, $p$ nonsignificant, with $\bar{X}_{O}=1.80$ and $\bar{X}_{Y}=1.44$; and more grandparent terms, $\boldsymbol{F}$ $(28,1)=11.06, p<.01$, with $\bar{X}_{O}=1.31$ and $\bar{X}_{Y}=0.31$. (For a similar finding from a contrasting approach, see LeVine and Price-Williams, 1974.) It seems that the older children tended to use kin terms to interrelate the dolls and label them as a family. They would say, "This is the mother, this is the father, this is the sister ... [etc]."

Perhaps before children acquire the social-cognitive capacity to explain or define kinship terms in terms of relationship, there exists a level at which children know that these terms are most appropriately extended as terms of reference to people who are connected or related. Preschoolers may consider only the most concrete and immediate aspects of connection, such as living together or loving (not fighting) "right now," yet their understanding of kinship terms may be less strictly "categorical" (i.e., limited to gender and age status) than Danziger (1957), Haviland and Clark (1974), Piaget (1928), and others have claimed. To put it another way, one facet of meaning, the extension, of kinship terms earlier includes the abstract "relational components" than does the definitional facet of meaning, intention (see Anglin, 1977). 


\section{Study 2}

This study examined how children sorted photographs of themselves and of strangers aged 1-70 years into categories derived from the results of Study 1. A photo-sorting task was used and because pilot work determined it to be too difficult for 2-year-olds, it was performed on an expanded sample of children aged 3-5 In this second task, children sorted head-and-shoulder photographs of people varying in age from 1 to 70 years. A photo of the child's own face was also included to be categorized, and thus the child's "age of self-identification" was determined (terminology of Daum, 1978).

In this second study, four questions were investigated. First, descriptively, was there a large or small amount of consensus or sharing in the way that the sample as a whole sorted the photos? Second, with respect to sorting the unfamiliar photos, developmental and sex differences were hypothesized. For the same reasons as Study 1, older children and girls were expected to show less "error" or random responding than younger children and boys. Third, sex differences were hypothesized for children's age self-identification. A pilot study in 1976 of 32 3-4-year-olds at the Educational Testing Service Child Care Research Center had determined that boys were much more likely than girls to categorize themselves as a big child than a little child, $X 2(2)=8.61$, $p<.05$. Thus, in the present study, boys were expected to categorize themselves in an older age group than girls. Last, developmental differences were hypothesized for the sorting of the stranger photos in terms of the ages grouped into each category. Lewis (Note 1) and Lewis, Edwards, Weistuch, and Cortelyou (Note 2) argue that a person's perspective on the age group of others depends on his or her own age. A person views the social world from a relative rather than absolute vantage point that changes as one's self matures. The age of the subject influences his or her age of transitions between categories. The present sample contains only a $2 \frac{1}{2}-$-year age span of subjects, however, and possibly this range is too restricted for any age differences to emerge.

\section{Method}

Subjects. The 16 oldest lab school children were retested the next autumn, plus 50 children of comparable age from a day-care center in a neighboring city and 18 children from the lab school. The total sample contained 42 girls and 42 boys aged 3.01 to 5.06 years (mean 4.29 years for girls, 4.33 for boys). The day-care children were Caucasian and differed from the lab school group primarily in that their mothers were more often employed, single parents. 
Procedure. In order to examine how children categorize people throughout the life span into age classes, the photographic stimuli of Study 1 were employed, supplemented by additional pictures. Two photo sets (A and B) were created containing 30 photos each: males and females of 15 target ages $(1,3,5,7,9,11,13,15,17,20,30$, $40,50,60$, and 70 years; for the adult photos, the person who posed was within \pm 2 of the target age).

As with Study 1 the photos used had been confirmed by pilot testing with adults to be good exemplars, that is, they "looked their age." Preschool children become easily fatigued by large numbers of photographs so that It was not possible to present each child with both many represented ages and many faces at each age. We desired to present many represented ages in order to gain a fine-grained understanding of preschool categorization of the entire life span, and the highly systematic results obtained (see below suggest the adequacy of the stimuli for this purpose^ Some earlier researchers (e.g., Britton \& Britton, 1969; Looft, 1971) have used schematic drawings rather than photos to avoid the problem of stimulus variation (how people look) at any real age, but here that method seemed undesirable because it allows for only a few ages to be depicted. Instead, care here was first taken to exclude nonexemplary photos, and then two photo sets (A and B) were constructed to provide two sample faces for each target age/sex category represented.

Either of two female college students or the author tested the subject child. First, she took the child's picture with a Polaroid camera and seated the child at a small table. The testing procedure (designed so that a child never chose among more than three categories at a time) was as follows for a girl subject: The tester pointed to two clear plastic boxes on the table and told the child to "put pictures of children here" (pointing to one box) and "pictures of grown-ups here" (pointing to the other). The tester then began to hand the child one by one photos of 15 females (either set A or B, in shuffled order). She frequently repeated for the child which box was for "children" and which for "grown-ups." While sorting, the child was free to move any pictures back and forth from one pile to another. In many cases a child protested that the 1-year-old photo was not either a "child" or a "grown-up" but instead a "baby." The tester allowed the child to place that photo on the table by itself. When the child had sorted the 15 photos, the tester temporarily put away the photos sorted as "grown-ups" and took the remaining "children" (and "baby"). Adding a third plastic box to the table, she told the child, "Now put pictures of babies here and little girls here and big girls here" (pointing 
to each box in turn) and again gave the child photos one by one to sort. Finishing this task, the tester handed over the photo of the child herself and instructed the child to put it into "the right box of girls." Then the tester put away the photos of female "children" and returned to the "grown-ups." Using two plastic boxes, the tester guided the child to sort into the categories of mothers versus grandmothers. Then the tester removed the set of 15 female photos, brought out the corresponding set of 15 male photos (A or B) and guided the child through the entire procedure (minus the sorting of the self photo) for the parallel set of male categories, grown-ups versus children; then baby, little boys versus big boys; then fathers versus grandfathers. For a boy subject, the procedure was the same except in reverse order, so that he, too, sorted same-sex photos first.

Test-retest reliability. Test-retest reliability over a 2 -month interval was measured for 25 subjects still at the day-care center in the summer. The average age of these subjects was 4.41 years at retesting. Reliability (percent of photos sorted the same way on both testings) averaged $94 \%$ per child.

\section{Results and Discussion}

For analysis, the total sample of 84 children was broken into four sex/age groups. Each of the subgroups $(N=21)$ contained the same proportion of nursery versus daycare children. The mean ages of the groups were 3.87 and 4.72 (girls) and 3.91 and 4.75 (boys).

The children demonstrated a great deal of consensus in the way that they sorted the photographs, indicating that these preschoolers showed much sharing in the meaning that they ascribed to the age group categories presented. For example, $76 \%$ of the total sample classified the 3-year-old girl as a little girl. Consensus (modal choice) for each sex/age object ranged from $54 \%$ to $100 \%$, averaging $74 \%$. Thus, over half the sample agreed on a correct age group for every social object. The children showed lowest percent agreement (least consensus) for modal choice concerning the male photos aged $5,7,13$, and 50 and female photos aged $5,11,13,15,40$, and 50 .

The sortings that the children displayed are seen in Figure 2. As the age of the depicted face increases, the number of children who place that face in a particular category changes. A category boundary represents a transition between age groups. The transition age between babies and little children is at 2 years, between little and 
big children at 6 years, between big children and parents at 14 years, and parents and grandparents at approximately 50 years. Notice that the differentiation between little and big children roughly corresponds to preschool age versus school age, and that adolescents are merged with parents.
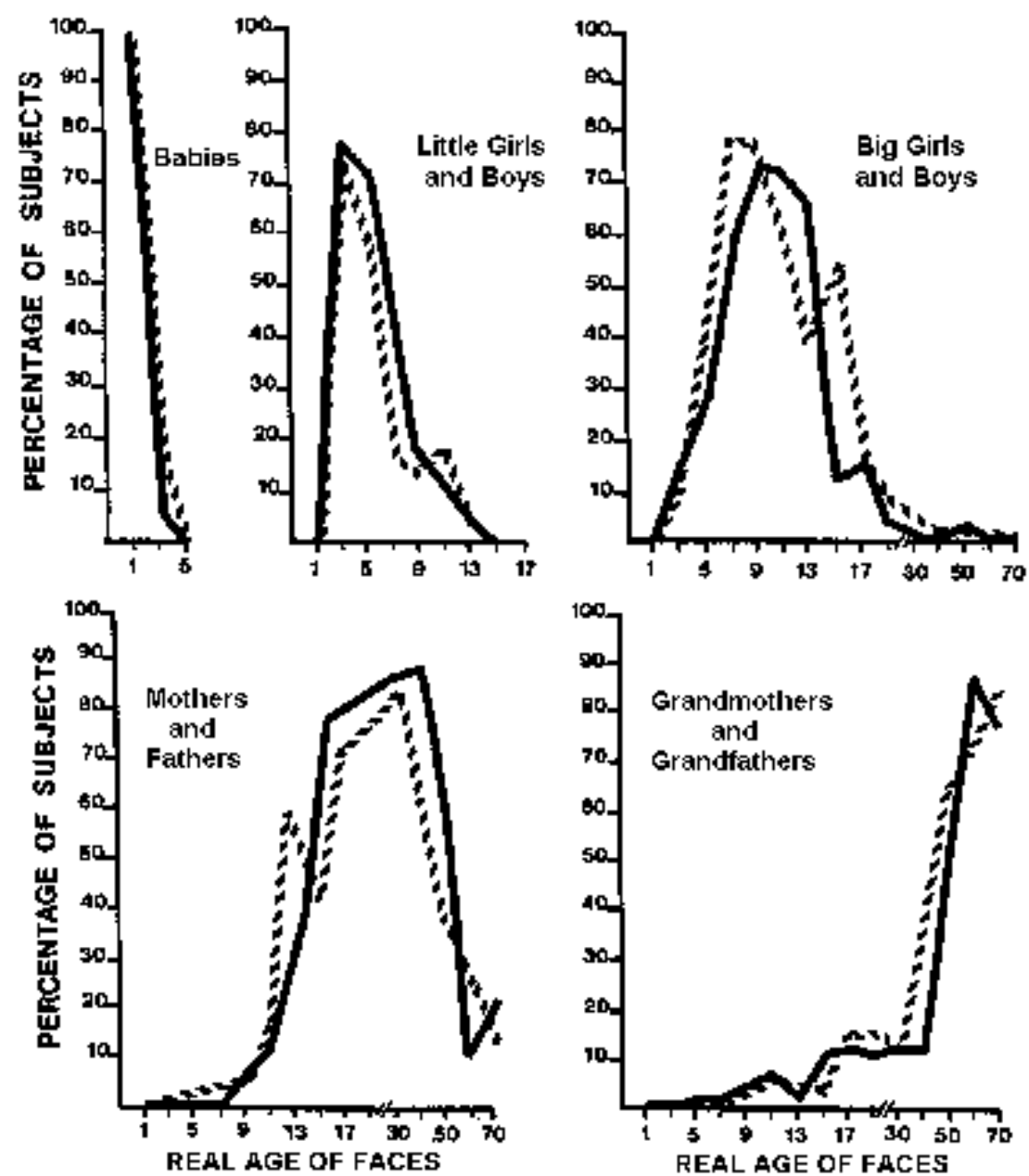

Fhotograph of tere Mala Funa

Figure 2. Percentage of subjects aged 3-5 years classifying faces of different ages into different categories

Lewis et al. (Note 2) have performed the same sorting task with adults aged 20-60 years. They find that adults, too, easily perform the task (averaging $86 \%$ consensus for each sex/age category). However, for adults the ages of transition between categories 
are in some ways very different from what they are for preschoolers. In particular, the age of transition from little to big children is around 13 years and from big children to parents between 17 and 20 years. (The age category, adolescents, was not included as a category for sorting, yet the adults nevertheless found a way to segment off the adolescent age group, in contrast to what preschoolers did.) Clearly, a person's perspective on other people's age group depends on his or her own relative maturity.

An analysis was performed of the children's "errors," counting as an error a departure from the group consensus answer for a particular sort (e.g., sorting the 3-year-old female as a big rather than little girl). Analysis of variance (subject sex $\times$ age $\times$ stimulus condition) indicated that, as hypothesized, younger children made more sorting errors, and the differences approached significance, $F(76, I)=3.34, p=.07$, for total numbers of errors; $\boldsymbol{F}(76,1)=3.67, p=.06$, for errors made on female photos considered separately. Boys did not make more errors than did girls, and stimulus condition (A or B) did not affect total number of errors.

How did children identify their own age category, that is, sort their self photo? All children identified themselves as either a big or little child (never as a baby), and, as hypothesized, boys were more likely to call themselves big than were girls, $X^{2}(1)=$ 3.88, $p<.05$. However, a clear interaction effect was present. Seventy-one percent of the younger boys versus 19\% of the younger girls, $43 \%$ of the older boys, and $52 \%$ of the older girls identified themselves as big, $X^{2}(3)=12.01, p<.01$. That is, comparing the younger children in the sample (aged 3.01-4.03), boys and girls tended to have different identifications (boys big, girls little). Comparing the older children (aged 4.03-5.06), boys and girls did not differ. Now about half of each group called itself big.

These findings were more complex than expected. The sex difference among the younger subjects (roughly aged 3 ) might be explained by the following reasoning: Perhaps during the early preschool years, boys more than girls want to identify themselves as big (rather than little) because they are beginning to form a gender identification and have realized that men are generally bigger than women. It is a well-known fact that children early notice the size and strength differences between men and women and attach great importance to them. For the very little boys, it would be doubly desirable to be big because big means both masculine and older. Viewing themselves as little would thus be especially problematic for young boys. Their cognitive immaturity at age 3 would make it impossible for them to truly coordinate the idea of 
big and little. (See Fischer \& Watson's [1981] discussion of the development of the cognitive ability to coordinate social roles during the preschool years.)

What happens, then, to change the identification of the older preschoolers so that boys come increasingly to identify themselves as little and girls as big? Perhaps the children become increasingly realistic about their true physical size and age position relative to other children, and better able to understand the relation of big to little. As the children approach the age of 5 , they come to understand that they are indeed bigger and older than infants, toddlers, and young preschoolers, yet are still not quite old enough for kindergarten and grade school. They are "betwixt and between," and appropriately, half of them now classify themselves as big, half as little.

The final question concerned whether additional age or sex differences emerged in the way that children sorted the stranger photos. To examine differences in sorting behavior, chi-squares were performed on the sorting of each of the 30 photos, taken one at a time, first using subject sex (two categories) as the independent variable, then subject age group (two categories). Then in order to look for sex $\times$ age interaction effects, sex/age groups (four categories) were used as the independent variable. The 50-year-old female photo was the only stimulus whose sorting was predictable-specifically, by subject age, $X^{2}(2)=10.77, p<.01$, and by sex/age, $X^{2}(6)=18.98, p<$ .01 . Older girls almost always sorted this stimulus as a grandmother (the group consensus answer), while other groups more often sorted it as a mother. This isolated result is difficult to interpret because it appears to fit no general pattern, and no specific interpretation is offered.

Additional chi-squares were next run using age self-identification (big child vs. little child) as an independent variable. This procedure was used because subjects age and sex had so definitely affected the sample of children in terms of age self-identification. The question arose whether sorting of the self photo would relate to the way that children sorted the other photos. Indeed, it did. Children who identified themselves as big were more likely than children who identified themselves as little to sort the following stimuli into an older age group: the 3 -year-old boy photo, $X^{2}(2)=15.50, p<.001$; 5 year-old boy $X^{2}(2)=8.27 p<.05$; 7-year-old boy $X^{2}(2)=20.21, p<.001$; 3-yearold girl, $X^{2}(3)=11.70, p<.01 ; 7$-year-old girl $X^{2}(2)=6.02, p<.05$; and 15-year-old girl, $X^{2}(2)=6.72, p<.05$ Thus the children's self-identification was consistently related to the way that they categorized the stranger photos of both sexes near to 
them in age (specifically, aged 3, 5, 7), illustrating how closely concepts of self and others are intertwined (Brooks-Gunn \& Lewis, 1979).

(This explanation, incidentally, does not account for the results with the 15-year-old female photo, which are difficult to interpret, and which we suggest relate only to idiosyncrasies of the photos used; see Figure 2 and the fact that the 13-year-old female photo was usually sorted as a mother, but the 15 year-old as a big girl.)

\section{Conclusion}

In conclusion, "age" groups and differences have a great saliency to young children, and preschoolers appear competent to use age group terms as an early, shared, and structured system to label and to classify the social world. Their capacity to use age group terms in a systematic way, in fact, stands in marked contrast to other aspects of their age understanding (such as assessing chronological ages, relating sex and age roles, and defining kinship terms relationally) that develop only much later during the middle childhood years.

Study 1 used dolls and photographs of faces in a free-labeling task to determine what terms of reference are most available to children aged 2-4 years as they attempt to label a social array. The study found that preschoolers, in contrast to toddlers studied by Brooks-Gunn and Lewis (1979), readily produced terms of reference for all age groups from infants to old people However, in terms of calling members of age pairs (e.g., the mother and father dolls) by the same or parallel labels, the children were more unstructured in their approach to adult than to child stimuli, suggesting that it was more difficult for them to fit the adult stimuli into a conceptual matrix based on dimensions of age and sex.

The older preschoolers and girls within the sample were expected to make finer age group distinctions than were the younger children and boys, and to be more systematic in imposing an age/sex structure on the array. However, only children's own age predicted the number of age distinctions made, and only sex (girls higher) predicted degree of structure, suggesting a different orientation in girls and boys rather than slower development in boys. Perhaps girls and boys equally were interested in, and able to make, age group distinctions, but girls were more sensitive to the pairwise order to the stimuli because they were more eager to discern connections or relations between stimuli. Evidence is accumulating for the presence of sex differences in 
social-cognitive tasks related to the social domain of age (e.g., judging chronological ages, defining and conserving kinship roles). I propose that age/size distinctions are equally salient and impressive to both boys and girls (see results of Study 2 as well), but girls tend to be particularly interested in variations and connections among people in the family, where age roles are especially prominent (see Jordan, 1980).

Study 2 was a categorization task based on photographs to determine 3-5-year-olds' self-identification, how much consensus existed in the way that children applied the labels derived from Study 1, and what were children's transition points between age group categories. The children's sorting behavior showed more "error" responding than did older ones. The results demonstrate that children aged 3-5 can readily segment the life span in a sensible way-though this preschool way of dividing up age groups differs from adult conceptualizations as measured by Lewis et al. (Note 2). From the preschool perspective, $\wedge^{*}$ appears that certain age groups of people (schoolaged children and adolescents) seem "bigger" and "older" than they do to more mature people further along the age continuum.

Sex differences were prominent in study 2 in how children identified themselves in terms of age group. Boys were significantly more likely than girls to sort themselves as a big rather than little child. However, it was only in the younger half of the sample that this happened. Among the older half of the sample, about half of each sex group called itself big and half little. These results for the younger preschoolers were interpreted in terms of their cognitive immaturity and resulting difficulties both in coordinating the ideas of big and little and comparing themselves to an objective dimension of size. The younger children could say that they were big (or "little") simply on the basis of wishing to be so. The young boys had a particular wish to call themselves "big" because they know that adult males are bigger than females.

The children's age self-identification actually tended to be congruent with their categorization of similar-aged peer stranger photos. That is, the children tended to classify themselves into the same category that they had earlier placed photos of 3-7 year-old peers, suggesting that they were not constructing their self-concept in isolation from their concepts of others. Social cognition from the earliest years necessarily involves comparison of self and others, of course. However, the congruence of the children's age self-identification and their classification of peer stranger photos provide a source of confidence in the sorting instrument used and the results obtained. 


\section{Notes}

1. Lewis, M. Newton, Einstein, Piaget and the concept of self. Invited address to the Jean Piaget Society, Philadelphia, May-June 1980.

2. Lewis, M., Edwards, C. P., Weistuch, L., \& Cortelyou, S. Age as a social cognition. Unpublished manuscript, Educational Testing Service, Princeton, N.J., 1981.

\section{References}

Anglin, J. M. Word object and conceptual development. New York: Norton, 1977.

Anglin, J. M. From reference to meaning. Child Development, 1978, 49, 969-976.

Britton, J. O., \& Britton, J. H. Discrimination of age by preschool children. Journal of Gerontology, 1969, 24, 457-160.

Brooks, J., \& Lewis, M. Infants' responses to strangers: Midget, adult, and child. Child Development, 1976, 47, 323-333.

Brooks-Gunn, J., \& Lewis, M. "Why Mama and Papa?" The development of social labels. Child Development, 1979, 50, 1203-1206.

Chambers, J. C, Jr., \& Tavuchis, N. Kids and kin: Children's understanding of American kin terms. Journal of Child Language, 1976, 3, 63-80.

Clark, E. V. On the child's acquisition of antonyms in two semantic fields. Journal of Verbal Learning and Verbal Behavior, 1972, 11, 750-758.'

Danziger, K. The child's understanding of kinship terms: A study in the development of relational concepts. Journal of Genetic Psychology, 1951, 91, 213-^232.

Daum, M. The dimension, correlates and measurement of age identification and age ascription. Dissertation Abstracts International, 1918, 39(3-B), 1538-1539.

Edwards, C. P., \& Lewis, M. Young children's concepts of social relations: Social functions and social objects. In M. Lewis \& L. A. Rosenblum (Eds.), The child and it's family. New York: Plenum, 1979.

Elkind, D. Children's conceptions of brother and sister: Piaget's replication study V. Journal of Genetic Psychology, 1962, 100, 129-136.

Field, T. F. Infant behaviors directed toward peers and adults in the presence and absence of mother. Infant Behavior and Development, 1979, 2, 47-54. 
Fischer, K. W., \& Watson, M. W. Explaining the Oedipal conflict. In K. W. Fischer (Ed.), Cognitive development. (New Directions for Child Development, No. 12.) San Francisco: Jossey-Bass, 1981.

Fogel, A. Peer versus mother directed behavior in 1-3-month-old infants. Infant Behavior and Development, 1979, 2, 215-226.

Furth, H. G. The world of grown-ups. New York: Elsevier-North Holland, 1980.

Greenfield, P. Who is dada? Language and Speech, 1973, 16, 34-^3.

Haviland, S. E., \& Clark, E. V. "This man's father is my father's son”: A study of the acquisition of English kin terms. Journal of Child Language, 1974, 1, 23-^7.

Jordan, V. B. Conserving kinship concepts: A developmental study in social cognition. Child Development, 1980, 51, 146-155.

Kogan, N., Stephens, J. W., \& Shelton, F. S. Age differences: A developmental study of discriminability and affective response. Journal of Abnormal and Social Psychology, $1961,62,221-230$.

Kohlberg, L. A cognitive-developmental analysis of children's sex role concepts and attitudes. In E. E. Maccoby (Ed.), The development of sex differences. Stanford, Calif.: Stanford University Press, 1966.

Kratochwill, T. R., \& Goldman, J. A. Developmental changes in children's judgments of age. Developmental Psychology, 1973, 9, 358-362.

Kuczaj, S. A. II, \& Lederberg, A. R. Height, age and function: Differing influences on children's comprehension of "younger" and "older." Journal of Child Language, $1977,4,395-\wedge 16$.

LeVine, R. A., \& Price-Williams, D. R. Children's kinship concepts: Cognitive development and early experience among the Hausa. Ethnology, 1974, 13, 25-44.

Lewis, M., \& Brooks-Gunn, J. Social cognition and the acquisition of self. New York: Plenum, 1979.

Lewis, M., \& Feiring, G. The child's social network: Social object, social functions, and their relationship. In M. Lewis \& L. A. Rosenblum (Eds.), The child and its family. New York: Plenum, 1979.

Looft; , W. R. Children's judgments of age. Child Development, 1971, 42, 1282-1284.

Looft, W. R., Rayman, J. R., \& Rayman, B. B. Children's judgments of age in Sarawak. Journal of Social Psychology, 1912, 86, 181-185. 
Nelson, K., Rescorla, L., Gruendal, J., \& Benedict, H. Early lexicons: What do they mean? Child Development, 1978, 49, 960-968.

Piaget, J. Judgment and reasoning in the child. London: Routledge \& Kegan Paul, 1928.

Piaget, J. The child's conception of time. London: Routledge \& Kegan Paul, 1969.

Schantz, G. U. The development of social cognition. In E. M. Hetherington (Ed.), Review of child development research (Vol. 5). Chicago: University of Chicago Press, 1975.

Smith, M. D. The acquisition of word meaning: An introduction. Child Development, $1978,49,950-952$.

Stevenson, J. W., Miller, L. K., \& Hale, G. A. Children's ability to guess the ages of adults. Psychological Reports, 1967, 20, 1265-1266.

Thomson, J. R., \& Chapman, R. S. Who is "Daddy" revisited: The status of two-yearolds' over-extended words in use and comprehension. Journal of Child Language, $1977,4,359-375$.

Watson, M. W., \& Fischer, K. W. Development of social roles in elicited and spontaneous behavior during the preschool years. Developmental Psychology, 1980, 16, 483494.

Whiting, B. B., \& Whiting, J. W. M. Children of six cultures: A psycho-cultural analysis. Cambridge. Mass.: Harvard University Press, 1975.

A preliminary version of this paper was presented as part of the symposium "Perception of Differences: Children's Understanding of Age, Race, and Handicaps" at the meetings of the American Psychological Association in Los Angeles, August 1981. I thank my excellent research assistants, Marcy Sala and Laurie Childs, and the teachers and children of the Vernon Street School and the University of Massachusetts Early Childhood Laboratory School. This research direction was begun while I was a postdoctoral fellow with Michael Lewis at Educational Testing Service, and his guidance and support are gratefully acknowledged.

Published in Child Development 55 (1984), pp. 440-452. Copyright (c) 1984 by the Society for Research in Child Development, Inc. All rights reserved. 